\title{
Fabrication and Characterization of a Solution Processed Flexible Thermal Sensor by Using Chemically Synthesized GO and rGO
}

\author{
Hakan Bozkurt \\ Department of Photonics \\ Izmir Institute of Technology \\ Urla-Izmir, Turkey \\ hakanbozkurt@iyte.edu.tr
}

\author{
Halide Diker \\ Department of Photonics \\ Izmir Institute of Technology \\ Urla-Izmir, Turkey \\ dikerhalide@gmail.com
}

\author{
Canan Varlikli \\ Department of Photonics \\ Izmir Institute of Technology \\ Urla-Izmir, Turkey \\ cananvarlikli@iyte.edu.tr
}

\begin{abstract}
Graphene oxide (GO) was reduced by ascorbic acid which is an environmental-friendly reductant and obtained sample was named as reduced GO (rGO). Stable dispersions of GO and rGO were prepared in N,N-Dimethylformamide (DMF). Compared to GO sample, rGO was determined to have more thermal stability, smaller sheet size and lower surface energy. GO and rGO dispersions were drop-casted on aluminum (AI) coated acetate substrate and used as thermal sensor. Fabricated sensors were tested from $25^{\circ} \mathrm{C}$ to $150{ }^{\circ} \mathrm{C}$. The sensors fabricated with GO, were not stabile against driven temperature changes. However, rGO ones, presented no thermal hysteresis effect after the first heating step. This sensor (Al/rGO/AI) acted like an NTC (Negative Temperature Coefficient) thermistor. The resistance of the rGO sensor was changed between $42 \mathrm{k} \Omega$ to $25 \mathrm{k} \Omega$ depending on the test temperature range $\left(25^{\circ} \mathrm{C}\right.$ to $\left.150{ }^{\circ} \mathrm{C}\right)$. Average beta value was calculated as $519.7649 \mathrm{~K}$.
\end{abstract}

Keywords - reduced graphene oxide, ascorbic acid, thermal sensor

\section{INTRODUCTION}

In recent years, rapid development in information technologies necessitates the usage of sensors that are integrated into daily life, industrial and also healthcare field applications [1]-[4]. Monitoring of the temperature is an important issue in the modern-life utilizations such as the automobiles, pharmaceuticals, robotic technologies, artificial intelligence, and food packaging applications [5]-[9]. Thermal sensor based on detection of resistivity changes is the most preferred sensor due to the good stability, fast responsivity, and high accuracy [7]. Metals, metal-oxides, ceramics, polymer-based and carbon-based materials (graphene, graphene oxide $(\mathrm{GO})$, reduced graphene oxide (rGO), carbon nanotube) are used for thermal sensing applications [7], [10]-[17]. Besides some parameters such as temperature coefficient of resistance and thermal hysteresis, being flexible, lightweight, easy-manufacturability and costefficiency are the other important requirements for the thermal sensors. Brittle and heavy structure of metals and ceramics limits their usage in flexible sensor applications, whereas graphene derivatives are good candidates for this field due to their extraordinary mechanical and electrical properties [7], [14].

GO and rGO are the most known graphene derivatives and are synthesized by the chemical route that allows the low-cost and large scale production [15]. Furthermore, thermal and electrical properties of those derivatives are completely

Scientific and Technological Research Council of Turkey (TUBITAK) (Project \#: 114M508) different from the pristine graphene due to having some functional groups and structural defects [18], [19]. These functional groups disrupt the zero-band gap structure of pristine graphene and led to a band structure shifting and thereby change the properties of the materials. Thus, various graphene-like materials can be obtained that have different sensing behavior based on owing functional groups and can be utilized for sensor applications in different ways. Chen et.al., used polydopamine modified GO (PGO) as thermosensitive sensor in fire alarm wallpaper application with low responsive temperature $\left(126.9^{\circ} \mathrm{C}\right)$, and fast response (2s) [20]. Hou et.al determined the thermal diffusivity of annealed graphene nanosheet (up to $300 \mathrm{~mm}^{2} / \mathrm{s}$ ) to be higher than that of cupper $\left(117 \mathrm{~mm}^{2} / \mathrm{s}\right)$ and silver $\left(170 \mathrm{~mm}^{2} / \mathrm{s}\right)$ metal films [21]. Temperature coefficient of resistance (TCR) of rGO sensor was reported as to be changed depending on either rGO concentration and working temperature region of sensor, i.e. TCR was $0.801 \% / \mathrm{K}$ and $-32.04 \% / \mathrm{K}$ for $303 \mathrm{~K}-373 \mathrm{~K}$ and $303 \mathrm{~K}-77 \mathrm{~K}$ region, respectively [14]. Thermal conductivity of epoxy/fiberglass composite that was used as glass fiberreinforced polymer composite was increased by $8.2 \%$ and $4.1 \%$ after modification with GO and rGO respectively [15]. Liu et.al. fabricated rGO based thermal sensor and determined that resistance of sensor decreased from $4.511 \mathrm{k} \Omega$ (at RT) to $4.040 \mathrm{k} \Omega$ (at $45^{\circ} \mathrm{C}$ ) for about $1.2 \mathrm{~s}$ [7].

Functional group differences of graphene derivatives allow the usage of them in various sensor applications and resulting in different performances. Choice of suitable material is the most important issue to develop a good thermal sensor. Therefore, temperature sensing properties of GO and rGO that was obtained by using environmentally-friendly reducing agent (ascorbic acid, is also known as Vitamin C), were performed in this study. Preliminary test results show that rGO film has lower resistivity and better stability than GO film at the applied temperature, between $25-150{ }^{\circ} \mathrm{C}$. These findings demonstrate that synthesized $\mathrm{rGO}$ is a good candidate for utilization in thermal sensor application.

\section{MATERIALS AND METHODS}

\section{A. Materials}

Ascorbic acid (Vitamin $\mathrm{C}$ ), hydrochloric acid $(\mathrm{HCl})$, methanol, N,N-Dimethylformamide (DMF) and Aluminum (Al) were purchased from Sigma Aldrich. All chemicals were used as received and they were all in analytical grade. Mica substrates were from SPI (mica grade V-4). Regular A4 acetate paper which is laser printable was used for substrate of sensor. 


\section{B. Instruments}

Structural characterization of synthesized reduced graphene oxide (rGO) was performed by using Rigaku Ultima IV X-Ray Diffractometer (XRD), Thermo Scientific K-Alpha Surface Analysis XPS spectrophotometer and Horiba, XploRA Raman Microscope. Morphological and electrical properties of rGO films were measured by Ambios Q Scope 250 model atomic force microscope (AFM) and Signatone S302-4 Four Point Probe, respectively. Al deposition was performed with a shadow mask by a vacuum evaporator, attached to an LC Technology Solutions glove box system. Keithley 2400 source meter was used for detecting the resistance changes of the sensors based on the temperature and the sensor was heated up to $150{ }^{\circ} \mathrm{C}$ by using ISOLAB hot plate.

\section{Synthesis of Reduced Graphene Oxide}

Graphene oxide (GO) was synthesized in previous study [22] and used as the raw material for the reduction reaction. Reduce graphene oxide (rGO) sample was synthesized as discribed; $9.73 \mathrm{mmol}$ ascorbic acid was added to $100 \mathrm{ml} \mathrm{GO}$ $(1 \mathrm{mg} / \mathrm{ml})$ aqueous dispersion and reduction reaction was carried out at $100{ }^{\circ} \mathrm{C}$ for 24 hours. The reaction solution was filtered by washing with pure water $\left(@ 60{ }^{\circ} \mathrm{C}\right.$ ). This filtered solid material was dried at $70{ }^{\circ} \mathrm{C}$ for 12 hours and obtained reduced graphene oxide sample was referred as $\mathrm{rGO}$. GO and rGO dispersions were prepared in DMF within $0.5 \mathrm{mg} / \mathrm{ml}$ via ultrasonic bath for 30 mins. Dispersion stabilities of them were $\sim 0.25 \mathrm{mg} / \mathrm{ml}$ after one week later. Stable dispersions were spin coated and drop casted on the mica and quartz substrate respectively to determine their morphological and electrical properties.

\section{Fabrication of Graphene Based Thermal Sensor}

Acetate substrates were prepared by cutting the A4 size acetate paper in $20 \mathrm{~mm} \times 20 \mathrm{~mm}$ dimensions. The substrates were cleaned mechanically by using acetone then isopropanol and were dried by applying nitrogen gas with a spray gun. After the cleaning process, substrates were placed into the evaporator system by attaching them to a shadow mask. Al deposition was done under 1E-6 mbar pressure. Thickness of the coating was $400 \mathrm{~nm}$. Stable GO and rGO dispersions were drop casted on $\mathrm{Al}$ coated acetate substrates. Later, they were annealed at $150{ }^{\circ} \mathrm{C}$ for 30 mins. by using hot plate. Device structure was given in Fig. 1.

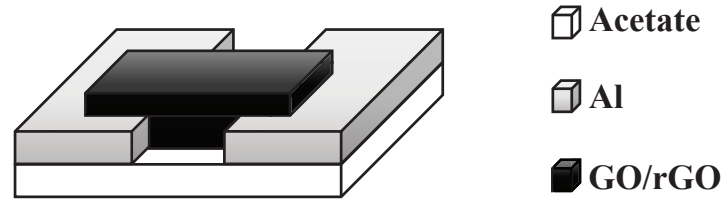

Figure 1. Bottom $\mathrm{Al}$ contacted GO and rGO sensors device structure

\section{RESULTS AND DISCUSSIONS}

\section{A. Structural and Morphological Characterization of $r G O$ Samples}

C1s XPS spectra of GO and rGO samples were given in Fig. 2. The peak that is related with the $\mathrm{C}=\mathrm{C}$ bonds (at $\sim 284.5$ $\mathrm{eV}$ ) was observed dominantly for the rGO sample. Most of the oxygenated functional groups were substantially removed from $\mathrm{GO}$ structure and $\mathrm{C}: \mathrm{O}$ ratio approximately 2.5 -fold increased after reduction i.e.; $\mathrm{GO}(\mathrm{C}: \mathrm{O} ; 2.04)$, rGO (C:O; 4.70).
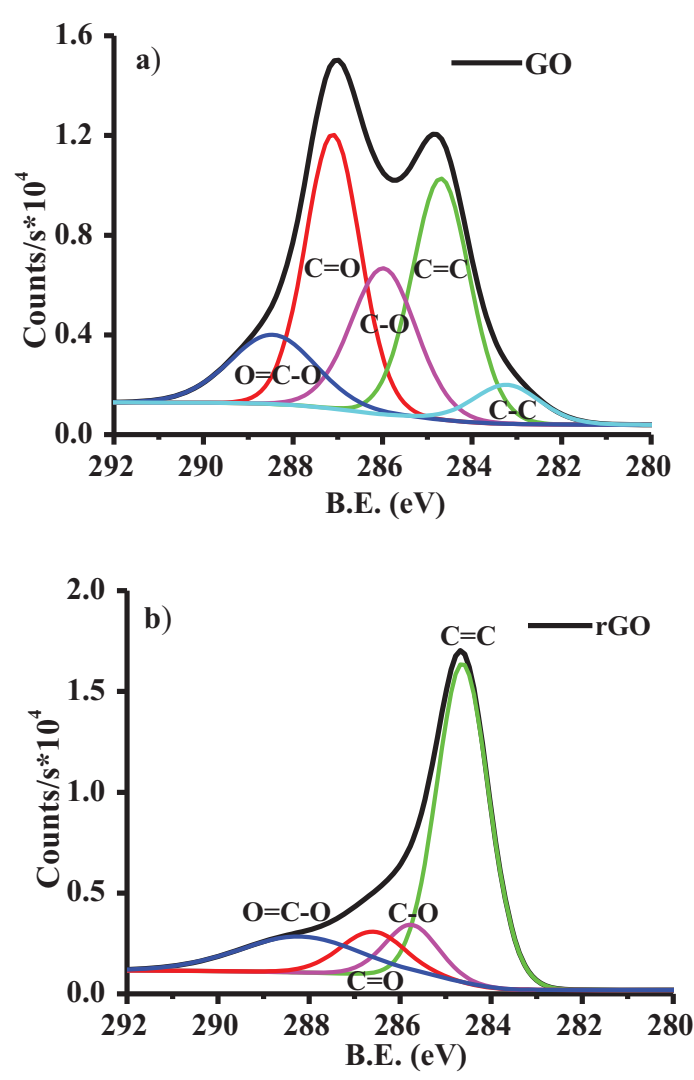

Figure 2. XPS spactra of a) GO and b) rGO samples

Characteristic XRD peak of the GO $\left(\sim 10^{\circ}\right)$ shifted to higher $(2 \theta)$ value $\left(\sim 25^{\circ}\right)$ for the rGO sample (Fig. 3a). This value indicates that the reduction of GO was carried out

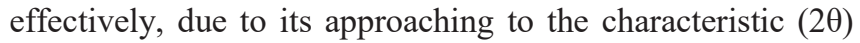
peak of graphite $\left(\sim 26^{\circ}\right)$ [23]. TGA curves of GO and rGO was presented in Fig. 3b. The sharp mass losses of $\mathrm{GO}$ at $230^{\circ} \mathrm{C}$ was not observed for the rGO as the oxygenated functional groups were reduced. The whole mass of GO was consumed at $650{ }^{\circ} \mathrm{C}$ whereas $\sim 70 \%$ of the mass of rGO was preserved even at $900{ }^{\circ} \mathrm{C}$. Additionally, $\mathrm{G}$ band RAMAN peak of GO $\left(1588 \mathrm{~cm}^{-1}\right)$ was red shifted for the $\mathrm{rGO}\left(1579 \mathrm{~cm}^{-1}\right)$ (Fig. $\left.3 \mathrm{c}\right)$. The approach of this peak to the characteristic $\mathrm{G}$ band peak of graphite $\left(\sim 1583 \mathrm{~cm}^{-1}\right)$ is the other evidence of the effective reduction [24].

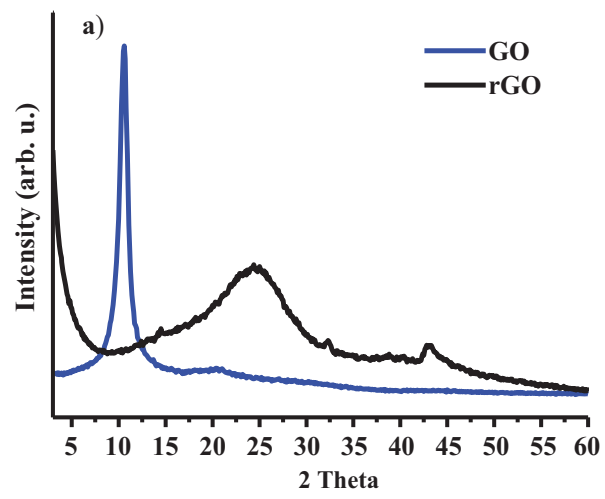



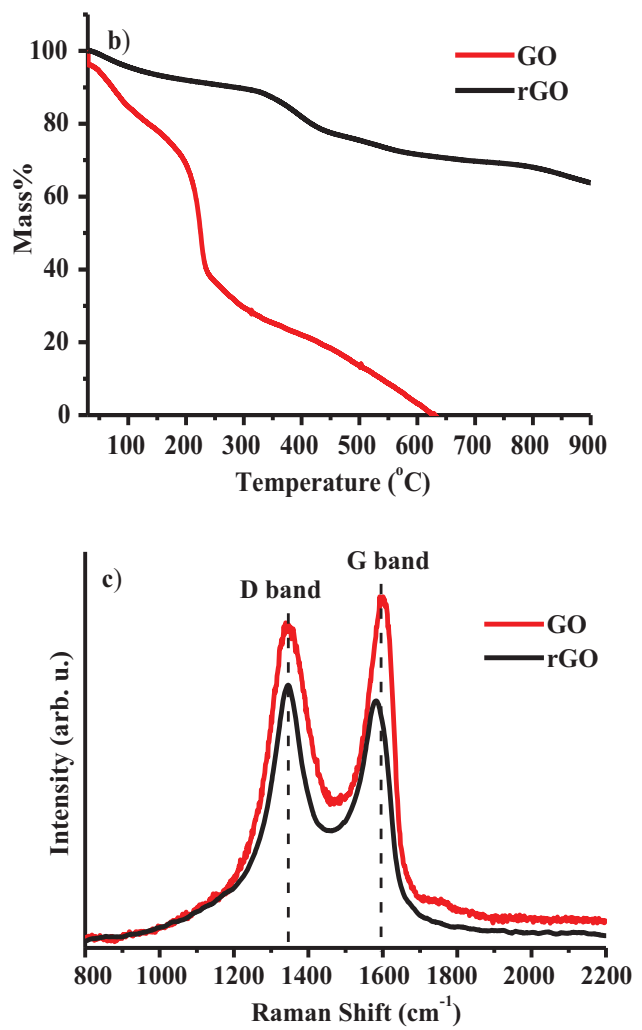

Figure 3. Characterization curves of GO and rGO samples a) XRD, b) TGA and c) RAMAN analysis

Fig. 4 shows the AFM images of GO and rGO film on mica substrate. Sheet size of the GO decreased after the reduction reaction and also sheet thickness of rGO (3.5 nm-14 $\mathrm{nm}$ ) was detected to be increased compared to that of GO (2$7.5 \mathrm{~nm})$. This increment could be explained by the formation of the bulk structure or existence of reaction residues (dehydroascorbic acid) on the sheets. Furthermore, the lower surface resistivity of $\mathrm{rGO}(0.25 \pm 0.01 \mathrm{M} \Omega / \mathrm{sq})$ film than GO $(0.85 \pm 0.11 \mathrm{M} \Omega / \mathrm{sq})$ film might indicate that conjugation and charge delocalization on the $\mathrm{rGO}$ sheet increased due to the removing of function groups from the structure.
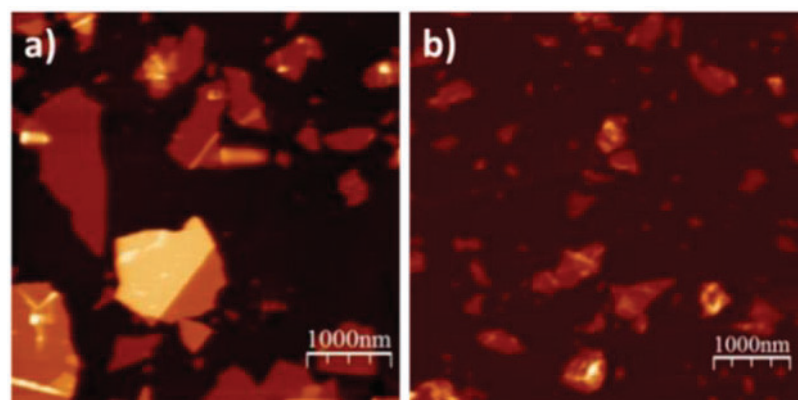

Figure 4. AFM images of a) GO film and b) rGO film

\section{B. Chracterization of Thermal Sensor}

Both GO and rGO coated device measurements were done under standard room conditions. Firstly, they were heated up to $150{ }^{\circ} \mathrm{C}$ by using hot plate then left for cooling. This heating and cooling cycle was applied twice. The resistance change on devices were measured at $25^{\circ} \mathrm{C}, 50{ }^{\circ} \mathrm{C}, 100{ }^{\circ} \mathrm{C}$ and $150{ }^{\circ} \mathrm{C}$, by using two spring loaded contacts touched onto the devices and attached the source meter.
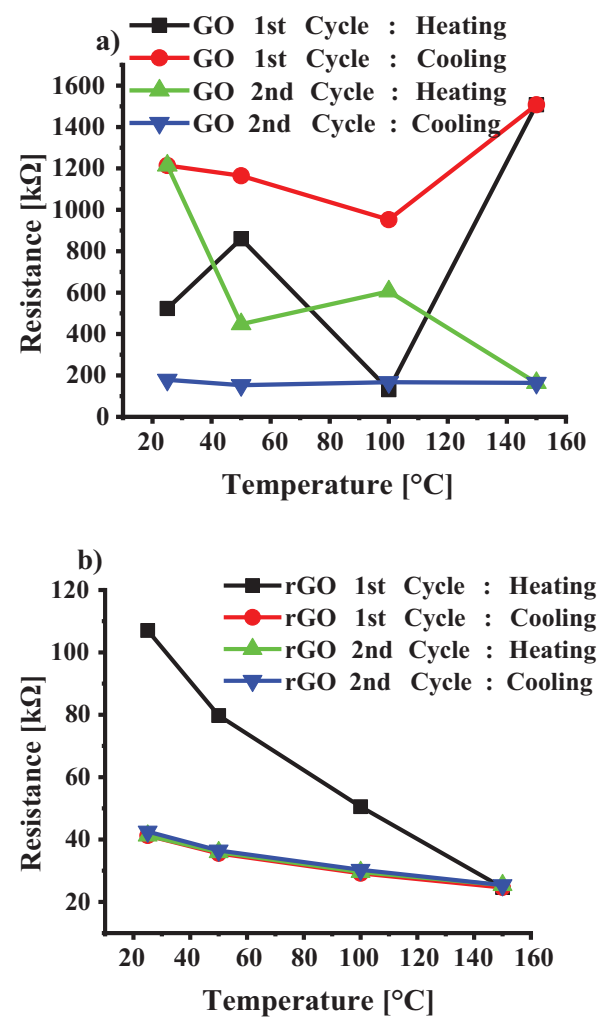

Figure 5. Resistance curves of GO and rGO devices by applied temperature a) $\mathrm{Al} / \mathrm{GO} / \mathrm{Al}$, b) $\mathrm{Al} / \mathrm{rGO} / \mathrm{Al}$ device

The sensor that contained GO layer showed positive thermal resistance behavior in the first cycle. But its response changed to negative in the second. However, the sensor, which was prepared with $\mathrm{rGO}$, presented similar resistivity values for both of the cycles, although its resistance values were much smaller than that of the GO one (Fig. 5). By using the below given Equation (1), $\beta$ value for the rGO device was calculated [25]:

$$
\beta=\left[\ln \left(\mathrm{R}_{1} / \mathrm{R}_{2}\right)\right] /\left[\left(1 / \mathrm{T}_{2}\right)-\left(1 / \mathrm{T}_{1}\right)\right]
$$

Where, $T_{1}$ and $T_{2}$ are Kelvin temperatures applied on the sensor and $R_{1}$ and $R_{2}$ are ohm unit resistance values measured at these temperatures. $\beta$ was calculated by using the curves on Fig. 5b, except first heating step, for each consecutive data point, and obtained values are given in Table 1.

TABLE I. REsistance AND Beta VALUES OF RGO AT DifFERENT TEMPERATURES

\begin{tabular}{|c|c|c|}
\hline Temperature $\left[{ }^{\circ} \mathbf{C}\right]$ & Resistance $[\mathbf{k} \boldsymbol{\Omega}]$ & $\boldsymbol{\beta}[\mathbf{K}]$ \\
\hline 150 & 24.583 & - \\
\hline 100 & 29.158 & 538.9836458 \\
\hline 50 & 35.531 & 476.7295445 \\
\hline 25 & 41.256 & 575.7360251 \\
\hline 50 & 35.943 & 531.3053513 \\
\hline 100 & 29.565 & 471.102842 \\
\hline 150 & 25.38 & 481.9999887 \\
\hline 100 & 30.303 & 559.8612427 \\
\hline 50 & 36.488 & 447.9353922 \\
\hline 25 & 42.571 & 594.2301693 \\
\hline \multicolumn{2}{|c|}{ Average $\boldsymbol{\beta}$ Value } & 519.7649 \\
\hline \multicolumn{2}{|c}{}
\end{tabular}




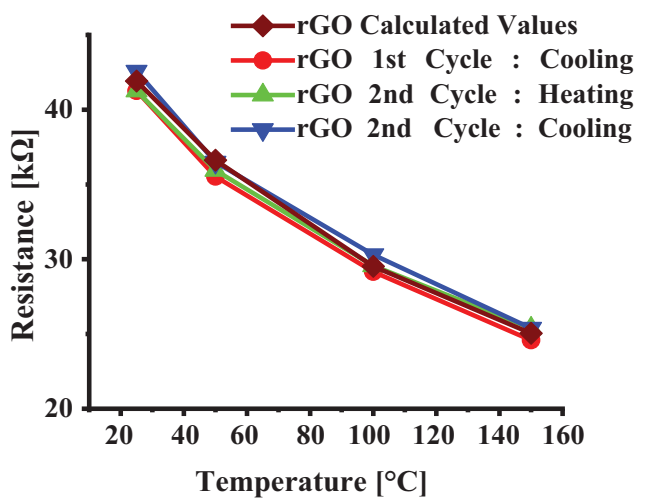

Figure 6. Measured and calculated resistance curves of $\mathrm{GO}$ and $\mathrm{rGO}$ devices by applied temperature

Average resistance at $25^{\circ} \mathrm{C}$ was calculated to be 41.9135 $\mathrm{k} \Omega$. By using this value and $\beta$ value in Equation (1), resistance at desired temperature could be found. Measured and calculated resistance values were compared in Fig. 6 and they presented quite similar values.

To avoid self-heating effects generating from the current change on the sensor, a $0.1 \mathrm{~mA}$ constant current circuit were designed by using Arduino Uno Board as a microcontroller. ADC (Analog to Digital Converter) pins were used to detect voltage difference on the reference $1 \mathrm{k} \Omega$ resistor. Via this voltage feedback, PWM output could be set on right value to get $0.1 \mathrm{~V}$ on $1 \mathrm{k} \Omega$. Constant, $0.1 \mathrm{~mA}$ current was allowed to pass on the thermal sensor. The circuit design is given in Fig. 7. Ambient temperature $\left[{ }^{\circ} \mathrm{C}\right]$ value was read on 0.96 Inch OLED screen which connected via I2C.

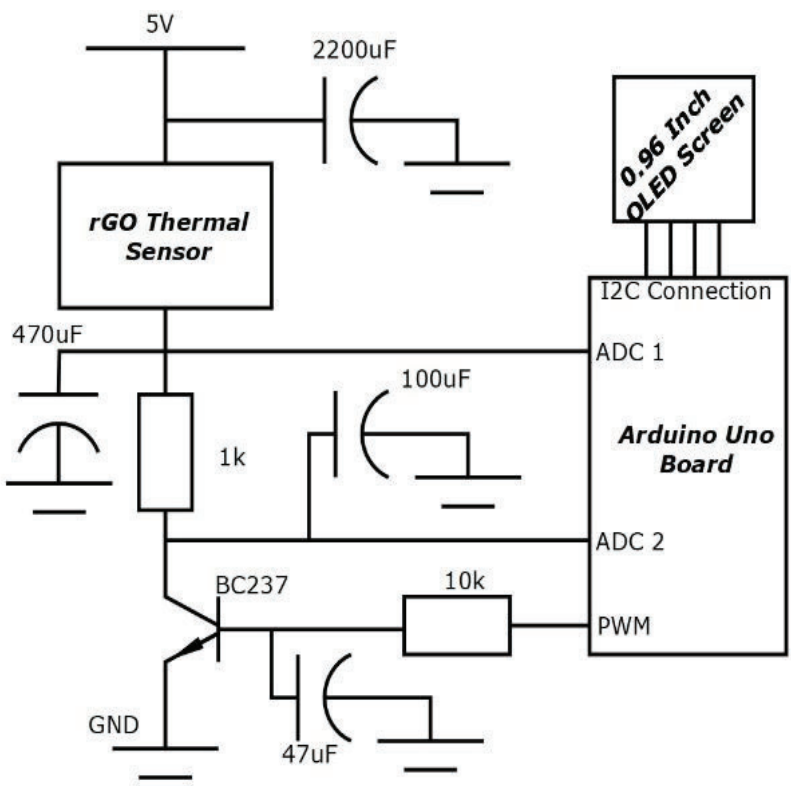

Figure 7. Circuit to detect temperature via fabricated thermal sensor

\section{CONCLUSION}

rGO sample was efficiently synthesized by reduction of GO via an environmental-friendly reducing agent, i.e. ascorbic acid. Both GO and rGO were used in the fabrication of a thermal sensor with a device structure of $\mathrm{Al} / \mathrm{GO}$ or $\mathrm{rGO} / \mathrm{Al}$. $\mathrm{rGO}$ presented stable thermal sensor properties and calculated values were compatible with measurements. By using a microcontroller the temperature of environment could be detected and displayed on screen. When the rGO sensor was placed on human hand (directly on skin), $36{ }^{\circ} \mathrm{C}$ was measured. Also, a heated surface was measured to be $129^{\circ} \mathrm{C}$ where a commercial multimeter TT-Technic A930C which has a temperature sensor gave this value as $127^{\circ} \mathrm{C}$.

$\mathrm{Al} / \mathrm{rGO} / \mathrm{Al}$ device structure showed NTC behavior. Fabricated flexible devices could be used as wearable thermal sensors after testing the resistance changes depending on the bending of substrate. Besides, by testing other metals to get ohmic contact with rGO, a PTC (Positive Temperature Coefficient) thermistor may also be fabricated.

\section{ACKNOWLEDGMENT}

Material synthesis and characterization part of this work was supported by the research project funds of Scientific and Technological Research Council of Turkey (TUBITAK) (Project \#: 114M508)

\section{REFERENCES}

[1] D. Johansson, K. Malmgren, and M. Alt Murphy, "Wearable sensors for clinical applications in epilepsy, Parkinson's disease, and stroke: a mixed-methods systematic review," J. Neurol., vol. 265, no. 8, pp. 1740-1752, 2018.

[2] M. Mardonova and Y. Choi, "Review of wearable device technology and its applications to the mining industry," Energies, vol. 11, no. 3, 2018.

[3] Q. Bao, Z. Yang, Y. Song, M. Fan, P. Pan, J. Liu, Z. Liao, and J. Wei, "Printed flexible bifunctional electrochemical urea-pH sensor based on multiwalled carbon nanotube/polyaniline electronic ink," J. Mater. Sci. Mater. Electron., vol. 30, no. 2, pp. 1751-1759, 2019.

[4] Y. Zhou, P. Zhan, M. Ren, G. Zheng, K. Dai, L. Mi, C. Liu, and C. Shen, "Significant stretchability enhancement of a crack-based strain sensor combined with high sensitivity and superior durability for motion monitoring," ACS Appl. Mater. Interfaces, vol. 11, no. 7, pp. 7405-7414, 2019.

[5] J. Brusey, D. Hintea, E. Gaura, and N. Beloe, "Reinforcement learningbased thermal comfort control for vehicle cabins," Mechatronics, vol. 50, pp. 413-421, 2018.

[6] D. Colucci, J. M. Prats-Montalbán, D. Fissore, and A. Ferrer, "Application of multivariate image analysis for on-line monitoring of a freeze-drying process for pharmaceutical products in vials," Chemom. Intell. Lab. Syst., vol. 187, no. January, pp. 19-27, 2019.

[7] G. Liu, Q. Tan, H. Kou, L. Zhang, J. Wang, W. Lv, H. Dong, and J. Xiong, "A flexible temperature sensor based on reduced graphene oxide for robot skin used in internet of things," Sensors, vol. 18, no. 5 , pp. $1-10,2018$.

[8] A. M. Andrew, A. Y. M. Shakaff, A. Zakaria, R. Gunasagaran, E. Kanagaraj, and S. M. Saad, "Early Stage Fire Source Classification in Building using Artificial Intelligence," 2018 IEEE Conf. Syst. Process Control, no. December, pp. 165-169, 2019.

[9] H. Yousefi, H. M. Su, S. M. Imani, K. Alkhaldi, C. D. Filipe, and T. F. Didar, "Intelligent Food Packaging: A Review of Smart Sensing Technologies for Monitoring Food Quality," ACS Sensors, vol. 4, no. 4, pp. 808-821, 2019

[10] T. Larsen, S. Schmid, L. Grönberg, A. O. Niskanen, J. Hassel, S. Dohn, and A. Boisen, "Ultrasensitive string-based temperature sensors," Appl. Phys. Lett., vol. 98, no. 12, pp. 10-13, 2011.

[11] Z. Bao and X. Chen, "Flexible and Stretchable Devices," Adv. Mater., vol. 28, no. 22, pp. 4177-4179, 2016.

[12] R. C. Webb, A. P. Bonifas, A. Behnaz, Y. Zhang, K. J. Yu, H. Cheng, M. Shi, Z. Bian, Z. Liu, Y. S. Kim, W. H. Yeo, J. S. Park, J. Song, Y. Li, Y. Huang, A. M. Gorbach, and J. A. Rogers, "Ultrathin conformal devices for precise and continuous thermal characterization of human skin," Nat. Mater., vol. 12, no. 10, pp. 938-944, 2013.

[13] Y. Zuo, Z. Gou, Y. Zhang, T. Yang, and W. Lin, "Thermally Responsive Materials for Bioimaging," Chem. - An Asian J., vol. 14, no. 1, pp. 67-75, 2019.

[14] P. Sehrawat, Abid, S. S. Islam, and P. Mishra, "Reduced graphene oxide based temperature sensor: Extraordinary performance governed 
by lattice dynamics assisted carrier transport," Sensors Actuators, B Chem., vol. 258, pp. 424-435, 2018.

[15] M. Rafiee, F. Nitzsche, J. Laliberte, S. Hind, F. Robitaille, and M. R. Labrosse, "Thermal properties of doubly reinforced fiberglass/epoxy composites with graphene nanoplatelets, graphene oxide and reducedgraphene oxide," Compos. Part B Eng., vol. 164, pp. 1-9, 2019.

[16] T. Q. Trung and N. E. Lee, "Flexible and Stretchable Physical Sensor Integrated Platforms for Wearable Human-Activity Monitoringand Personal Healthcare," Adv. Mater., vol. 28, no. 22, pp. 4338-4372, 2016.

[17] M. L. Hammock, A. Chortos, B. C. K. Tee, J. B. H. Tok, and Z. Bao, "25th anniversary article: The evolution of electronic skin (E-Skin): A brief history, design considerations, and recent progress," Adv. Mater., vol. 25, no. 42, pp. 5997-6038, 2013.

[18] O. C. Compton and S. T. Nguyen, "Graphene oxide, highly reduced graphene oxide, and graphene: Versatile building blocks for carbonbased materials," Small, vol. 6, no. 6, pp. 711-723, 2010.

[19] C. Botas, P. Álvarez, P. Blanco, M. Granda, C. Blanco, R. Santamaría, L. J. Romasanta, R. Verdejo, M. A. López-Manchado, and R. Menéndez, "Graphene materials with different structures prepared from the same graphite by the Hummers and Brodie methods," Carbon N. Y., vol. 65, pp. 156-164, 2013.

[20] F. F. Chen, Y. J. Zhu, F. Chen, L. Y. Dong, R. L. Yang, and Z. C. Xiong, "Fire Alarm Wallpaper Based on Fire-Resistant Hydroxyapatite Nanowire Inorganic Paper and Graphene Oxide Thermosensitive Sensor," ACS Nano, vol. 12, no. 4, pp. 3159-3171, 2018.

[21] Z. L. Hou, W. L. Song, P. Wang, M. J. Meziani, C. Y. Kong, A. Anderson, H. Maimaiti, G. E. Lecroy, H. Qian, and Y. P. Sun, "Flexible graphene-graphene composites of superior thermal and electrical transport properties," ACS Appl. Mater. Interfaces, vol. 6, no. 17, pp. 15026-15032, 2014.

[22] H. Diker, G. B. Durmaz, H. Bozkurt, F. Yeşil, and C. Varlikli, "Controlling the distribution of oxygen functionalities on GO and utilization of PEDOT:PSS-GO composite as hole injection layer of a solution processed blue OLED," Curr. Appl. Phys., vol. 17, no. 4, pp. 565-572, 2017.

[23] S. Abdolhosseinzadeh, H. Asgharzadeh, and H. Seop Kim, "Fast and fully-scalable synthesis of reduced graphene oxide," Sci. Rep., vol. 5, p. $10160,2015$.

[24] V. H. Pham, T. V. Cuong, S. H. Hur, E. Oh, E. J. Kim, E. W. Shin, and J. S. Chung, "Chemical functionalization of graphene sheets by solvothermal reduction of a graphene oxide suspension in N-methyl-2pyrrolidone," J. Mater. Chem., vol. 21, no. 10, pp. 3371-3377, 2011.

[25] https://www.ametherm.com/thermistor/ntc-thermistor-beta 